\title{
Family Structure and Age at Menarche: A Children-of-Twins Approach
}

\author{
Jane Mendle, Eric Turkheimer, Brian M. D’Onofrio, \\ Stacy K. Lynch, and Robert E. Emery \\ University of Virginia
}

\author{
Wendy S. Slutske \\ University of Missouri-Columbia
}

Nicholas G. Martin

Queensland Institute of Medical Research

\begin{abstract}
Girls who grow up in households with an unrelated adult male reach menarche earlier than peers, a finding hypothesized to be an evolutionary strategy for families under stress. The authors tested the alternative hypothesis that nonrandom selection into stepfathering due to shared environmental and/or genetic predispositions creates a spurious relation between stepfathering and early menarche. Using the unique controls for genetic and shared environmental experiences offered by the children-of-twins design, the authors found that cousins discordant for stepfathering did not differ in age of menarche. Moreover, controlling for mother's age of menarche eliminated differences in menarcheal age associated with stepfathering in unrelated girls. These findings strongly suggest selection, and not causation, accounts for the relationship between stepfathering and early menarche.
\end{abstract}

Keywords: menarche, pubertal timing, family stress, children of twins, stepfathering

Menarche is an event laden with personal, biological, and social significance. Because the timing of pubertal development varies across individuals, menarcheal age serves as an easily identifiable marker for developmental status relative to same-age peers. Research suggests that an earlier rate of physical development in girls correlates with a disturbing number of detrimental outcomes compared with on-time or later maturation. These include depression, substance abuse, eating pathology, body dissatisfaction, externalizing behavior, risky sexual behavior, abortion, breast cancer, and obesity (Blyth, Simmons, \& Zakin, 1985; Caspi \& Moffitt, 1991; Graber, Lewinsohn, Seeley, \& Brooks-Gunn, 1997; Keel, Fulkerson, \& Leon, 1997; Mezzich et al., 1997; Stice, Presnell, \& Bearman, 2001; Udry, 1979; Wellens et al., 1992).

Given this myriad of diverse, negative correlates of early menarche, it is important to investigate factors that contribute to pubertal timing. One notable effect is that menarche occurs at an earlier age among girls raised in stressful family circumstances

Jane Mendle, Eric Turkheimer, Brian M. D’Onofrio, Stacy K. Lynch, and Robert E. Emery, Department of Psychology, University of Virginia; Wendy S. Slutske, Department of Psychological Sciences, University of Missouri-Columbia; Nicholas G. Martin, Queensland Institute of Medical Research, Queensland, Australia.

This research was supported, in part, by W. T. Grant Foundation Grant AA07535, National Institute on Alcohol Abuse and Alcoholism Grant AA000264, and the National Alliance for Research on Schizophrenia and Depression.

We thank the staff of the Genetic Epidemiology Unit at Queensland Institute of Medical Research for assistance in data collection, especially Alison Mackenzie for coordination, and the twins and their children for cooperation in this research. We also thank Bruce Ellis for his helpful comments on this article.

Correspondence concerning this article should be addressed to Jane Mendle, Department of Psychology, University of Virginia, Box 400400, Charlottesville, VA 22902. E-mail: jm4ky@virginia.edu
(Doughty \& Rodgers, 2000; Jones, Leeton, McLeod, \& Wood, 1972; Kim \& Smith, 1998; Moffitt, Caspi, Belsky, \& Silva, 1992; Surbey, 1990). Belsky, Steinberg, and Draper (1991) have suggested an evolutionary explanation for this phenomenon. Specifically, they hypothesized that early childhood environment influences reproductive strategies that individuals adopt later in life. A stressful family environment-characterized by family conflict, absence of a biological father, poverty, and resultant insufficient parenting - predisposes girls to develop an internalizing disorder that lowers their metabolism, thereby inciting a weight gain that accelerates menarche. Unstable parental relationships during childhood subsequently lead girls to believe that resources are limited, people untrustworthy, and relationships opportunistic. They replicate their parents' mating-oriented reproductive behavior, tending to have multiple sexual partners and erratic relationships. In contrast, girls from more harmonious family environments exhibit slower sexual development, which in turn facilitates more stable relationships in adulthood.

Paternal investment theory, an extension of psychosocial acceleration ideas, posits that the developmental pathways presaging adult reproductive behavior are especially sensitive to the father's family role and parenting behavior (Draper \& Harpending, 1982; Ellis, 2004). Paternal investment theory is not inconsistent with Belsky et al. (1991) but rather a more specific subcontext of the general childhood stress articulated by those authors (Ellis, 2004). The quality of paternal care is believed to affect sexual development independent of other stressors that may be present in the family system.

Certainly, research supports both psychosocial acceleration and the paternal investment variant. Parental warmth, positive family relationships, and paternal involvement in child rearing are related to a comparatively later age of menarche (Ellis, McFadyenKetchum, Dodge, Pettit, \& Bates, 1999; Graber, Brooks-Gunn, \& Warren, 1995). Conversely, increased family conflict, divorce, and 
longer durations of father absence correlate with an earlier menarcheal onset (Moffitt et al., 1992; Romans, Martin, Gendall, \& Herbison, 2003; Surbey, 1990; Wierson, Long, \& Forehand, 1993). Father-daughter relationships are particularly predictive of menarche timing, and the quality of the father-daughter relationship is more strongly associated with rate of physical maturation than the quality of the mother-daughter relationship (Ellis et al., 1999).

Maturational onset seems especially sensitive to the presence of a stepfather (Ellis, 2004). Stepfathering predicts menarcheal age better than absence of a biological father, and a longer duration of stepfather presence correlates with earlier ages of menarche (Ellis $\&$ Garber, 2000). The magnitude of this association increases as conflict between a girl's mother and stepfather increases. Interestingly, animal studies offer additional support for the stepfatheringmenarche association: A variety of mammals_-including baboons, mice, deer, and lemmings - demonstrate accelerated onset of menarche when unrelated adult males are introduced into a colony, a phenomenon attributed to pheromonal activity and referred to as the male effect (Colmenares \& Gomendio, 1988; Ellis, 2004).

Collectively, this body of literature reinforces that certain environmental stressors tend to be associated with an acceleration of approximately 4-6 months in age at menarche. However, attempts to verify some of the more specifically causal aspects of Belsky et al.'s (1991) hypothesis have been less fruitful. In particular, Moffitt et al. (1992) found that the effect of a stressful childhood environment on age at menarche was mediated neither by weight gain nor by internalizing symptoms at age 7 , as would be consistent with Belsky et al. In fact, mother's age of menarche seems to be a better predictor of daughter's age of menarche than socioeconomic, contextual stressors such as mother's education, age at first marriage, and employment status of mother and/or current husband (Campbell \& Udry, 1995). Because early menarche is associated with early sexual intercourse and consequent single motherhood, it may be that mothers predisposed to raise children without a biological father in the home genetically transmit an early menarcheal age to their daughters (Caspi, 1998; Surbey, 1990).

In accordance with this alternative hypothesis, genetic influences on age at menarche are well documented. Correlations for age at menarche are consistently higher among monozygotic (MZ) than among dizygotic (DZ) twins (Doughty \& Rodgers, 2000; Meyer, Eaves, Heath, \& Martin, 1991; Rowe, 2002; Treloar \& Martin, 1990). Across four birth cohorts of twins, Treloar and Martin (1990) found that $61 \%-68 \%$ of the variance in menarche was accounted for by genetic effects. Other studies have yielded slightly lower heritability estimates for menarche, ranging from .44 (Rowe, 2000) to .54 (Doughty \& Rodgers, 2000). In a twin analysis of the items in Petersen et al.'s Pubertal Development Scale, Mustanski, Viken, Kaprio, Pulkkinen, and Rose (2004) estimated heritability of a combined latent pubertal timing factor at $88 \%$.

Mustanski et al.'s (2004) results were unusual in that they obtained an effect, albeit small, for shared environment on age at menarche. In the majority of genetically informed analyses of menarche, however, the variance not accounted for by genetic influences has primarily been attributable to nonshared environmental factors (e.g., Doughty \& Rodgers, 2000; Rowe, 2000). Although negligible shared environmental contributions are certainly pervasive in behavior genetics literature (see Daniels \&
Plomin, 1985; Dunn \& Plomin, 1990; Turkheimer \& Waldron, 2000), Rowe (2000) has argued that contextual stressors such as stepfather presence, family conflict, and insufficient parenting should be considered common environmental effects and would therefore accelerate the age at menarche of multiple siblings reared in the same household. Whereas this is certainly possible, it is also worth considering that familywide stressors may affect children in different ways and therefore emerge as components of nonshared environment in analyses (Turkheimer \& Waldron, 2000). Moreover, as Ellis (2004) has observed, the high estimates (at least $50 \%$ ) of nonadditive genetic variance obtained in some studies (e.g., Treloar \& Martin, 1990) may inflate heritability estimates at the expense of shared environmental effects.

Most research on the genetic origins of menarche has been conducted using only female relatives. However, there may be paternal as well as maternal influences on age of menarche. In fact, the same genetic factors that influence fathers' likelihood to abandon marriages may contribute to an earlier age of menarche in their daughters. Shorter alleles of the X-linked androgen receptor $(A R)$ gene are associated with aggression, impulsivity, high number of sexual partners, and divorce in males and with early age of menarche in females (Comings, Muhlemann, Johnson, \& MacMurray, 2002). In fact, many of the pathological outcomes associated with early menarche may simply result from an individual's propensity to develop such disorders. As Caspi and Moffitt (1991) have noted, a transitional developmental stage such as puberty tends to intensify and accentuate pretransition differences between individuals, thereby highlighting the emergence of deleterious symptoms and behaviors.

Because researchers obviously cannot randomly assign girls to fathering conditions, it is difficult to disentangle the extent to which uncontrolled environmental variables such as stepfathering or absence of a biological father affect age at menarche independent of the parents' genetic or environmental predilection to bear children with early menarcheal ages. Genetically informed data analyses are often advantageous in isolating potential familial confounds or eliminating selection biases. Dick, Rose, Viken, and Kaprio (2000), for example, effectively utilized a cotwin control comparison among twins discordant for age at menarche to establish that the earlier maturing twin was more likely to engage in smoking and drinking at a younger age than the later maturing one. However, family environmental variables such as those associated with the Belsky et al. (1991) hypothesis present a conundrum for researchers: Twin children are rarely discordant for major home environmental factors.

In such instances, a children-of-twins (CoT) design becomes vital for resolving questions of potential confounds or elucidating possible mediating variables (D’Onofrio et al., 2003; Gottesman \& Bertelsen, 1989; Rutter, Pickles, Murray, \& Eaves, 2001). Finding a sample of twin children discordant for stepfather status, for example, would be difficult, if not impossible. However, twin parents discordant for having stepfathers for their offspring are relatively frequent. Previous investigations of the Belsky et al. (1991) hypothesis have used unrelated control groups (i.e., age of menarche in children raised without stepfathers has been compared with age of menarche in children raised with stepfathers). This design, however, confounds the causal effects of stepfathering on early menarche with genetic and shared environmental predispositions to pubertal timing. Discordant twin comparisons eliminate 
the family-level confounds that may influence timing of menarche, as the comparison is made within a single family. Daughters raised in the presence of stepfathers can be compared with their cousins (the daughters of the mother's discordant cotwin) raised without stepfathers.

Furthermore, a comparison of the stepparenting effects in the children of MZ and DZ twins can potentially discriminate whether confounds in the association between stepfathering and menarche are mediated via genetics or shared environment. If there is a within-pair difference between the daughters of discordant DZ pairs but not between daughters of discordant MZ pairs, it suggests that the confound is primarily genetic. This is because DZ twins differ in genetic endowment and shared environment, whereas MZ twins differ only in their shared environment.

In summary, although the evolutionary hypothesis provides a plausible explanation for the documented association of paternal absence and earlier age at menarche, the posited causal relationship may in fact be explained by uncontrolled genetic and environmental influences. Girls who experience early menarche are more likely to be of lower socioeconomic status, experience psychological difficulties, and transmit likelihood of earlier development to their children (e.g., Mustanski et al., 2004; Stattin \& Magnusson, 1990; Udry, 1979). These are potential confounds that cannot be controlled in research that compares age of menarche among unrelated individuals. It may therefore be the case that previous investigations of the Belsky et al. (1991) hypothesis have overestimated the causal relationship between menarche and childhood stress variables. Ellis (2004) has discussed the importance of reevaluating the Belsky hypothesis, noting that "genetically controlled research designs that incorporate environmental measures are greatly needed" (p. 945). The CoT design allows a unique opportunity to examine genetic and shared environmental selection and, therefore, test the alternative hypothesis of family confounds.

\section{Method}

\section{Participants}

Mothers. Data on age at menarche in a sample of twin mothers were taken from a longitudinal study conducted by the Australian National Health and Medical Research Council Twin Registry (ATR). The ATR consists of a sample of volunteer twins recruited through media, schools, and other resources. Twins were born between 1893 and 1965, with a majority born after 1939 (25th percentile $=1939)$. Between 1980 and 1993, twins participated in a longitudinal assessment of three health and behavior surveys assessing the following domains: demographics, twinning, lifestyle, physical health, anxiety, depression, personality, and social attitudes. The first assessment, known as the Canberra Study, was collected via a mailed questionnaire during the early 1980 s $(N=8,183$ individual twins; 69\% response rate; Jardine \& Martin, 1984). Complete twin pairs who participated in the Canberra Study were mailed a second questionnaire, the Alcohol Cohort Follow-Up I Study (ALC1), in 1988-1989 $(N=$ 6,327 individuals; $83 \%$ response rate; Heath \& Martin, 1994). The third survey, the Semi-Structured Assessment for the Genetics of Alcoholism Study (Phase 1), was conducted using a telephone interview completed in 1992-1993 ( $N=5,889$ individual twins; 86\% response rate; Heath et al., 1997). Tests for self-selection biases in the longitudinal sample have not found detectable differences in risk for abnormal behavior between those who dropped out of the study and those who participated at multiple time points (Heath et al., 1997; Slutske et al., 1998). All participants were Caucasian, which is reflective of the predominantly Caucasian population in Australia for this birth cohort rather than an intentional sampling design. A more detailed description of the data collection methodology and instruments used for the longitudinal study may be found in D'Onofrio et al. (2006) or Heath and Martin (1994).

Offspring. The data on age at menarche and childhood environment in offspring of twins were drawn from a larger study designed to explore the intergenerational transmission of psychopathology and detrimental outcomes associated with parental divorce. Between 1998 and 2001, data were collected from offspring of twins in the ATR in four targeted subgroups and in a control group. The four at-risk groups comprise twins with a history of one or more of the following: alcohol dependence, conduct disorder, depression, and/or divorce. These subgroups were used to guarantee an adequate sample size of offspring from families with histories in the domains of interest. If either twin met criteria for one of the targeted groups, offspring from both twins were recruited for the study. (However, both twins were not required to have children for sample inclusion, as data on nonparent twins still provided necessary familial information.) The control group, approximately a quarter $(24 \%, n=601)$ of the participating offspring, was based on twin pairs in which neither cotwin met any of the at-risk criteria. A majority of the offspring $(51 \%, n=1,296)$ came from nuclear families in which the twin parent did not meet any of the criteria.

Offspring recruitment was based on information provided by the twin parents. The adult twins, who had previously participated in ATR research, were asked for consent to contact their children. Once consent was obtained, the offspring were notified of the study and, if willing, completed a telephone interview and mailed survey. Offspring reported on demographic characteristics, general health, childhood family environment, externalizing behavior, substance use (including alcohol and tobacco), depression, and perceived family history of alcohol-related problems. A subsample of participants $(n=176)$ were reinterviewed to establish the reliability of the instrument. This second participation occurred on average 1.08 years (range $=0.51-1.62$ years) after initial assessment. In total, 2,554 offspring from 889 twin pairs ( $431 \mathrm{MZ}, 458 \mathrm{DZ} ; 82 \%$ response rate) participated in the data collection. The sample used for the current analyses comprises the 1,284 female children of female twins (from 712 families) with available menarche data. Ages ranged from 14 to 38 at time of assessment $(M=24.5)$.

\section{Measures}

Menarche. As adults, mothers reported age at menarche (in months and years) during the first two waves of mailed questionnaire data collection, which were conducted approximately 8 years apart (the Canberra and ALC1 studies). Reports of menarche across the two assessments correlate .86. Offspring also reported age of menarche retrospectively as part of a mailed questionnaire battery. Test-retest reliability of age of menarche in a subsample of offspring $(n=87)$ was also established at .86 .

Given the age range of the offspring sample, it is possible that some girls might not have experienced menarche by the age at which they participated in the study. However, out of the 78 girls in our sample under the age of 18 , only one was missing menarche data-either because she had not yet experienced menarche or for another unrelated reason. Although this participant (aged 17 at the time the data were collected) could obviously not be used in the menarche analyses, we did use information on her stepfathering status in analyses of her relatives.

Childhood stress. Information on early childhood environment was obtained from offspring during a telephone interview. Four variables indicative of Belsky et al.'s (1991) concept of childhood stress were examined: divorce, being raised by both biological parents in the household, presence of a stepfather in the household, and absence of biological father in child rearing. Sample sizes for these variables are reported in Table 1.

Reports of stepfathering from siblings within the same family were not always in agreement. There were 76 girls from 48 families (5.9\%) who reported having a stepfather in the household prior to menarche. An 
Table 1

Mean Age at Menarche by Childhood Stress Variables

\begin{tabular}{lcrrr}
\hline \multicolumn{1}{c}{ Variable } & $M$ & $S D$ & $n$ & $d$ \\
\hline No stepfather & 13.06 & 1.43 & 1,172 & .38 \\
Stepfather & 12.53 & 1.39 & 112 & \\
Raised by both bio parents & 13.05 & 1.44 & 1,035 & .15 \\
Not raised by both bio parents & 12.84 & 1.42 & 249 & \\
No divorce & 13.05 & 1.43 & 1,036 & .14 \\
Divorce & 12.85 & 1.42 & 248 & \\
No separation from bio father & 13.05 & 1.43 & 1,093 & .17 \\
Bio father separation & 12.80 & 1.43 & 191 & \\
\hline
\end{tabular}

Note. $\quad$ Bio $=$ biological

additional 36 girls from 23 families did not report having a stepfather, although their siblings did. An investigation of these discrepancies showed that in 6 families the discrepancy resulted from a legitimate age difference among the siblings (e.g., an older sibling was past the age of menarche or no longer in the home when a younger sibling reported a stepfather). Other discrepancies seemed to result from divergent perceptions of the role of a mother's live-in boyfriend. Including the discrepant families, 71 of the 712 families in our sample $(10 \% ; n=112$ children $)$ had at least one child report presence of a stepfather during childhood.

For means comparisons, we coded children as having a stepfather if any child in that family reported a stepfather. However, additional analyses were conducted on the subsample of discrepant families to ensure that our method of coding provided accurate results. Moreover, the hierarchical linear models (described below) used in our analyses also accounted for within-family disagreements in stepfather presence in the model design. To accommodate discrepancies and genetic relatedness between participants for the hierarchical linear modeling (HLM) analyses, the stepfather status of the children and families was measured with three dichotomous variables. The first assigned a value of 1 to children who reported having a stepfather prior to menarche and a value of 0 to children who did not report stepfathering. The second assigned a value of 1 to children in a family if any of the mother's children reported a stepfather at any time during childhood. The third variable took a value of 1 if any children of either twin mother in a pair reported having a stepfather.

\section{Analyses}

Because the CoT design is not widely used, it is essential to be clear about the purpose and focus of our analyses. Two different types of analyses were conducted: descriptive comparisons of group means and a series of hierarchical linear models.

Means comparisons. As an initial step in the descriptive means comparison, the mean age at menarche of children in families without a particular childhood stress variable was compared with the mean age of children in families with that stressor, to establish whether girls with the stressors did in fact experience menarche at an earlier age. The means comparison was then extended to incorporate comparisons of groups of children based on the status of the mother's cotwin, which we refer to as the avuncular relationship. These comparisons provide a cotwin control for the hypothesis of a causal relationship between childhood stress variables and early menarche (D’Onofrio et al., 2003; Gottesman \& Bertelsen, 1989; Rutter et al., 2001).

To illustrate the logic behind the avuncular means comparisons, it may be helpful to consider the example of a pair of twin mothers discordant for having a stepfather for their children. That is, the children of Twin 1 are raised by their mother and stepfather, whereas the children of Twin 2 are raised by their mother and biological father. If the presence of a stepfather has a causal effect on age at menarche, the children of Twin 1 should exhibit earlier ages of menarche than the children of Twin 2 . To verify the
Belsky et al. (1991) hypothesis, we would expect only those girls who have stepfathers to display a lowered age of menarche. However, if some uncontrolled third variable shared between the twin mothers mediates the association between stepfathering and age at menarche, girls who have step-uncles but not stepfathers will display an age of menarche comparable to girls with stepfathers but not step-uncles.

A shared familial confound can be mediated along either genetic or shared environmental pathways. Adding zygosity into the avuncular means comparison can discriminate which pathway better accounts for a putative association between variables. If there is a difference in age of menarche among daughters of discordant DZ pairs but not MZ twin pairs, it suggests that the confound is primarily genetic. This is because the DZ parents differ in their genes and their shared environment, whereas MZ twins differ only in their shared environment. If there is a difference in both discordant MZ and DZ pairs, we can infer that the confound is more likely to be environmental. It is important to note that whereas zygosity and means comparisons may be used to identify likelihood and origin of a family-level confound, they cannot identify the confound per se.

HLM. We used a sequence of hierarchical linear models to examine the effects obtained through the avuncular means comparisons with more sophisticated regression techniques that allow for appropriate significance testing of the effects of interest, while controlling for other variables. HLM is an advantageous approach for two reasons. First, HLM is able to accommodate differing numbers of observations per family. Therefore, mothers with many children are not weighted more heavily than mothers with few children (as is the case in simple comparisons of means). Second, HLM is designed to account for the multiple levels of relationships between individuals in the sample (Bryk \& Raudenbush, 1992), particularly in the standard errors of the estimated regression coefficients. Because family data are nested according to the genetic relatedness between participants, children within the same nuclear family and twin mothers within a pair are not independent observations. HLM's inherent accommodation of different levels of clustering in data makes it particularly suitable for analyses of complex family designs.

In a CoT design, there is a maximum of three different levels of concurrent analysis. Level 1 is the individual child level and mimics the results of a simple regression of age at menarche on stepfather presence, while accounting for the genetic relationships among participants. Level 2, the twin mother level, incorporates effects attributable to each offspring's nuclear family. Level 3, the twin family level, uses data aggregated from both twin pairs. A schematic of the three levels of the model, and the familial relations between participants, is provided in Figure 1.

As an initial step in a five-model sequence of analyses, we fit an unconditional means model (Model 1), with age of menarche as an outcome variable and no predictor variables, to decompose the age at menarche variance into components attributable to variation among twin families, among mothers within twinships, and among children within mothers. To understand the remaining progression of the model sequence, it will again be helpful to consider the paradigmatic case of stepfather presence as a variable indicative of the type of stress discussed in the Belsky et al (1991) hypothesis. In Model 2, each child's self-report of stepfather presence prior to menarche (coded dichotomously) is used to predict age at menarche. The results of this individual-level model indicate whether stepfathering is predictive of menarcheal age, while accounting for clustering at the twinship and twin mother levels.

Model 3 estimates separate coefficients of the relationship between stepfathering and age at menarche at the individual child and twin mother levels. The twin mother predictor took a value of 1 if any of a mother's children reported having a stepfather, and was 0 otherwise. The child-level predictor is each child's deviation from the twin mother predictor. The child-level predictor is therefore equal to 0 in all families in which the children agreed about the presence or absence of a stepfather. In families in which the children disagreed, it takes a value of 1 for the children who reported having a stepfather and 0 for those who did not. This model 


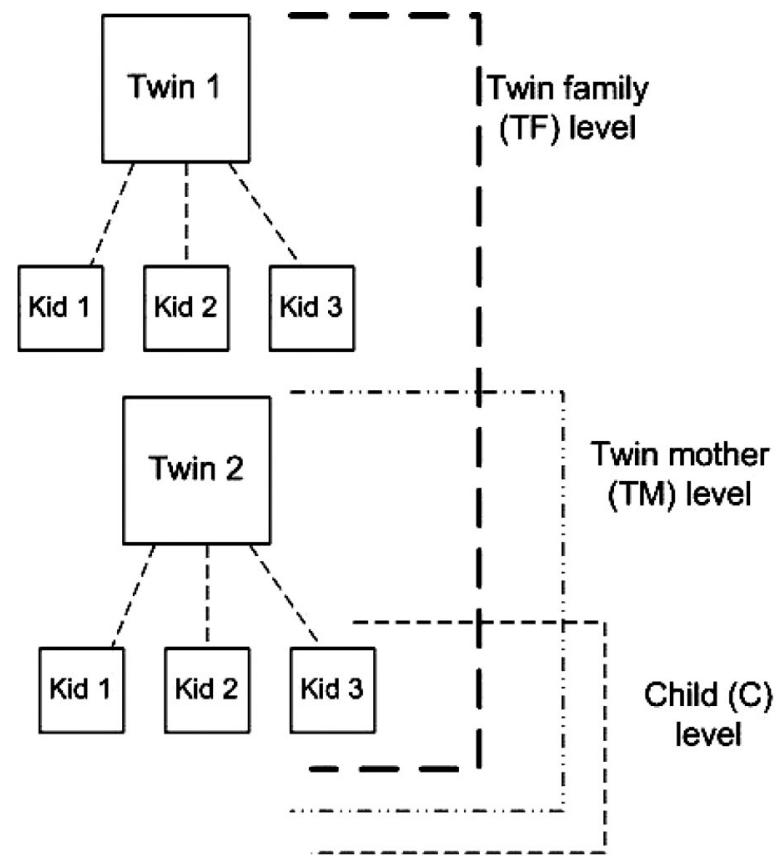

Figure 1. Levels in a children-of-twins hierarchical linear model.

estimates whether mothers who provide stepfathers have daughters with earlier age of menarche than those who do not, while simultaneously controlling for differences in age at menarche between siblings who disagree about their stepfathering status.

Model 4 further expands the representation of familial relations into the full, three-level analysis. At the Level 3, or twin family level, the dichotomous predictor takes a value of 1 if any of the children of either twin in a pair reported having a stepfather. The twin mother predictor is calculated as a deviation from the twin family predictor; like the child-level predictor in Model 3, it takes a value of 0 for all children in families for which the twin mothers share a stepfathering status. In discordant families (in which one twin mother provided a stepfather but the other did not) it takes a value of 1 for the children born to the mother providing the stepfather. The individual child-level predictor is calculated in the same way as for Model 3-as the deviation of individual children's reports of stepfathering from the twin mother status. Finally, Model 5 incorporates the mean age of twin mothers' menarche as a covariate at the twin family level, and the deviation of each twin's age of menarche from the pair mean as a covariate at the twin mother level. D'Onofrio et al. (2005) provide additional explanation on this modeling technique.

Accelerated failure time models. Although all of our participants were reporting retrospectively and all but 7 reported having experienced menarche (i.e., there was almost no censoring in the data), we also reconducted our hierarchical linear models using a survival analysis technique known as the accelerated failure time model. This was done to ensure that either right-censoring or the slightly positive skewed distribution of age at menarche did not generate inaccurate results. The accelerated failure time model may be used as an alternative to the Cox regression model for survival analysis and is obtained by regressing the logarithm of the survival time over the covariates (Wei, 1992; Wei \& Glidden, 1996).

\section{Results}

Initial means comparisons indicated that there was not a significant difference in age at menarche associated with children who reported divorce, separation from father during childhood, or lack of both biological parents in the household. We did replicate the reported association between stepfather presence and earlier age at menarche (see Table 1). Girls with stepfathers had a mean onset of menarche $(M=12.52, S D=1.43) 6$ months prior to that of girls without stepfathers $(M=13.06, S D=1.38)$. This represents a difference of approximately one half a standard deviation. Because stepfathering was the only variable to demonstrate a reasonably sized effect on age at menarche, we conducted additional analyses only for this variable.

Table 2 presents results from a cotwin control comparison of age at menarche and stepfather presence. We divided the data into four groups based on stepfathering status: 1,111 children whose twin mothers were concordant for not having a stepfather for their children, 61 children who had a stepfather but no step-uncle (i.e., their first cousins did not have a stepfather), 62 children who had a step-uncle but no stepfather, and 50 children who had both stepfathers and step-uncles. Although offspring of twins concordant for not having stepfathers for their children had a mean age of menarche later than offspring of twin pairs concordant for stepfathering $(d=.39)$, there was no difference between the mean ages at menarche for daughters in the two types of discordant pairs (i.e., girls with stepfathers but not step-uncles did not differ from girls with step-uncles but not stepfathers; $d=.05$ ). This pattern of results implicates some form of uncontrolled shared familial confound as opposed to a causal effect of stepfathering, which would presumably be specific to daughters with stepfathers as opposed to step-uncles.

A familial confound can be mediated along either genetic or shared environmental pathways. In theory, monozygotic and dizygotic twin pairs can be used to establish whether a confound is genetic or environmental in origin. These means are presented in Table 3. Dividing the concordant and discordant twin pairs according to zygosity proved inconclusive. The means of MZ twins concordant for not having stepfathers for their children did not differ from the means of MZ twins concordant for having stepfathers $(d=.07)$, whereas a difference was found in the DZ twin pairs $(d=.68)$. Within the discordant MZ twin pairs, children raised by the twin providing a stepfather had an age of menarche slightly earlier than children raised by the cotwin without a stepfather $(d=.21)$; the opposite pattern occurred in children of the discordant DZ pairs $(d=-.17)$. These ambiguous results do not negate the evidence of a family confound obtained by the avuncular comparisons; rather, it seems that splitting the data into increasingly more specific categories compromised the sample size within each category to such an extent that we were unable to discriminate whether the confound was genetic or environmental. Given these results, incorporating zygosity into our hierarchical

Table 2

Mean Age at Menarche by Cotwin Control Groups

\begin{tabular}{lccr}
\hline \multicolumn{1}{c}{ Group } & $M$ & $S D$ & $n$ \\
\hline Concordant no step & 13.09 & 1.43 & 1,111 \\
Discordant no step & 12.59 & 1.41 & 61 \\
Discordant step & 12.52 & 1.42 & 62 \\
Concordant step & 12.54 & 1.37 & 50 \\
\hline
\end{tabular}

Note. $\quad$ step $=$ stepfather. 
Table 3

Mean Age at Menarche by Zygosity and Cotwin Control Group

\begin{tabular}{lccr}
\hline \multicolumn{1}{c}{ Group } & $M$ & $S D$ & $n$ \\
\hline MZ concord no step & 13.02 & 1.40 & 528 \\
MZ discord no step & 12.89 & 1.17 & 36 \\
MZ discord step & 12.61 & 1.52 & 33 \\
MZ concord step & 12.92 & 1.29 & 25 \\
DZ concord no step & 13.14 & 1.46 & 583 \\
DZ discord no step & 12.16 & 1.62 & 25 \\
DZ discord step & 12.41 & 1.30 & 29 \\
DZ concord step & 12.16 & 1.37 & 25 \\
\hline
\end{tabular}

Note. $\mathrm{MZ}=$ monozygotic; $\mathrm{DZ}=$ dizygotic; concord $=$ concordant; discord $=$ discordant; step $=$ stepfather.

linear models would not have provided additional clarification and therefore was not included as a step in the analyses.

Menarche means were also examined in families with discrepancies among individual sibling reports of stepfather status (see Table 4). Within the discrepant families, the mean age of offspring who reported no stepfather was comparable to the mean age of offspring who reported a stepfather.

The HLM results are summarized in Table 5. Each model produced two sets of results: random effects, representing the variance in age at menarche attributable to the three levels of clustering in the design (twin families, mothers, and individual children), and fixed effects, representing the regressions of age at menarche on stepfathering, including an intercept. Model 1 includes only the random effects and an intercept. The magnitude of the random effects in Table 4 can be used to describe the degree of clustering of age at menarche in the different levels, expressed as intraclass correlations, that is, a ratio of the variance at a given level to the total variance of age at menarche. The intraclass correlation for twinships is equal to $.12(.25 /(.25+.21+1.60)$, and the intraclass correlation for twin mothers within twinships is $.10(.21 /(.25+.21+1.60)$. The remaining $78 \%$ of the variability in age at menarche is among siblings within twin mothers.

In Model 2, stepfathering is introduced as a fixed predictor. The predicted intercept is 13.02 . The estimated regression coefficient for this effect $(b=-.34, p<.04)$ is an expression of the overall phenotypic relationship between stepfathering and age at menarche: Girls with stepfathers are predicted to achieve menarche approximately 4 months prior to girls without stepfathers.

Model 3 estimates separate effects for stepfathering reported by daughters born to the same mother, and the deviations of individual daughters' reports from the family status. In this case, the effect of the twin mother status is once again substantial and significant $(\mathrm{b}=-.39, p<.02)$, but the individual deviations are not. This suggests that the effect of coming from a family in which there is a stepfather is more salient than whether an individual child reported having a stepfather in a family in which siblings disagreed about stepfather status.

Model 4 introduces a predictor at the twin family level, describing whether either mother in a pair was reported to have provided a stepfather. This variable becomes the significant predictor $(\mathrm{b}=$ $-.44, p<.05)$; the predictors at the twin mother and individual child levels are no longer significant. Because step-uncles and stepfathers contribute equally to the twinship mean, this result confirms the finding from the means analysis that step-uncles are as predictive of earlier menarche as stepfathers, indicating a familial confound.

In Model 5, we included the fixed effects of two levels of maternal age at menarche. We expressed maternal age at menarche as a twin family mean (the average of the twin mothers' ages at menarche) and as a deviation of the twin mothers from the twin family mean. Estimated in this model were the twin family mean of maternal age at menarche $(b=.22$ years of daughter age at menarche per year of maternal age at menarche, $p<.01)$ and the twin mother deviation score $(\mathrm{b}=.20, p<.01)$. With maternal menarche controlled, the effect of twinship mean stepfathering was essentially unchanged $(\mathrm{b}=-.37, p<.04)$.

Finally, we reran all of the above models employing an accelerated failure time model, by using the log of age at menarche as the dependent variable. Although the parameter estimates were altered by the change of scale in the outcome, there were no changes in the magnitude of the results or their statistical significance (see Table 6).

\section{Discussion}

Early age of menarche has been associated with childhood stressors such as family conflict, father absence, and lack of a traditional two-parent family structure. Given that children cannot be randomly assigned into stressful childhood environments, ascertaining the causality between family experience and child outcome is riddled with empirical confounds and interpretative challenges. A genetically informed design eliminates some of the ambiguities inherent in more traditional methodologies, by accounting for genetic and shared environmental influences on age at menarche. Our analyses used a sample of children of twins. This methodology retains the advantages of the more common twin design, while permitting an evaluation of the effects of parenting variables for which twin children would be unlikely to differ.

Although variables such as divorce and presence of both biological parents in the household were mildly associated with earlier menarche, the effect in our sample was smaller than obtained in previous studies. Father absence also did not predict age at menarche in at least one other study (Graber et al., 1995). Ellis and Garber (2000) and Ellis (2004) have suggested that stepfather presence is a better predictor of age of menarche than father absence, as it indicates lower quality paternal investment. In accordance with their findings, our results show that girls raised in families with stepfathers exhibit a significantly earlier age of menarche than girls raised without stepfathers.

This phenotypic effect, however, is attenuated when genetic relations between participants are considered. The presence of a step-uncle was as strongly predictive of early menarche as pres-

Table 4

Mean Age at Menarche Among Discrepant Siblings

\begin{tabular}{lllll}
\hline \multicolumn{1}{c}{ Group } & $M$ & $S D$ & $n$ & $d$ \\
\hline No reported step & 12.30 & 1.25 & 10 & .09 \\
Reported step & 12.42 & 1.17 & 26 & \\
\hline
\end{tabular}

Note. $\quad$ step $=$ stepfather. 
Table 5

Hierarchical Linear Models of Stepfathering and Age at Menarche

\begin{tabular}{|c|c|c|c|c|c|}
\hline Parameter & Model 1 & Model 2 & Model 3 & Model 4 & Model 5 \\
\hline \multicolumn{6}{|c|}{ Random effects } \\
\hline Families & $\begin{array}{l}.25^{*} \\
(.11)\end{array}$ & $\begin{array}{l}.23^{*} \\
(.11)\end{array}$ & $\begin{array}{l}.21 * \\
(.11)\end{array}$ & $\begin{array}{l}.20^{*} \\
(.11)\end{array}$ & $\begin{array}{l}.02 \\
(.13)\end{array}$ \\
\hline Twins & $\begin{array}{l}.21^{*} \\
(.14)\end{array}$ & $\begin{array}{l}.22 * \\
(.14)\end{array}$ & $\begin{array}{l}.22^{*} \\
(.14)\end{array}$ & $\begin{array}{l}.23 * \\
(.14)\end{array}$ & $\begin{array}{l}.22 \\
(.16)\end{array}$ \\
\hline Children & $\begin{array}{l}1.60^{*} \\
(.11)\end{array}$ & $\begin{array}{l}1.60^{*} \\
(.11)\end{array}$ & $\begin{array}{l}1.60^{*} \\
(.11)\end{array}$ & $\begin{array}{l}1.60 * \\
(.11)\end{array}$ & $\begin{array}{l}1.61^{*} \\
(.13)\end{array}$ \\
\hline \multicolumn{6}{|c|}{ Fixed effects } \\
\hline Intercept & $\begin{array}{c}13.00^{*} \\
(.04)\end{array}$ & $\begin{array}{c}13.02 * \\
(.05)\end{array}$ & $\begin{array}{c}13.04 * \\
(.05)\end{array}$ & $\begin{array}{c}13.07 * \\
(.05)\end{array}$ & $\begin{array}{c}12.95^{*} \\
(.07)\end{array}$ \\
\hline $\begin{array}{l}\text { Stepfathering } \\
\text { Individual child report }\end{array}$ & & $\begin{array}{c}-.34 * \\
(.16)\end{array}$ & & & \\
\hline Individual child report deviation & & & $\begin{array}{l}.31 \\
(.30)\end{array}$ & $\begin{array}{l}.32 \\
(.30)\end{array}$ & $\begin{array}{l}.27 \\
(.38)\end{array}$ \\
\hline Twin mother status & & & $\begin{array}{l}-.39 * \\
(.17)\end{array}$ & & \\
\hline Twin mother deviation & & & & $\begin{array}{l}.005 \\
(.24)\end{array}$ & $\begin{array}{l}.14 \\
(.27)\end{array}$ \\
\hline Family status & & & & $\begin{aligned}-.44 * \\
(.16)\end{aligned}$ & $\begin{aligned}-.37 * \\
(.18)\end{aligned}$ \\
\hline \multicolumn{6}{|l|}{ Maternal menarche } \\
\hline Twin pair mean & & & & & $\begin{array}{l}.22^{*} \\
(.03)\end{array}$ \\
\hline Twin mother deviation & & & & & $\begin{array}{l}.20^{*} \\
(.04)\end{array}$ \\
\hline
\end{tabular}

Note. Values in parentheses are standard errors.

$* p<.05$.

ence of a stepfather. It does not seem necessary for a child to experience the direct environmental influence of a stepfather to exhibit an accelerated age of menarche-as long as she is genetically related to someone who does have a stepfather. In a pair of twin mothers of which only one raises her children with a stepfather, the offspring of both twins are equally likely to display early age of menarche. It therefore appears that some genetic or shared environmental confound accounts for the earlier association found in female children living with stepfathers.

Unfortunately, owing to sample size limitations, we were unable to determine whether the familial confound was genetic or environmental in origin. Therefore, although it is possible that the heritability of timing of menarche is the salient operative in the menarche-stepfathering association, the results obtained by our analyses may also have been mediated along shared environmental pathways. To illustrate, consider the possible confound of marital conflict, which is also associated with earlier puberty (e.g., Romans et al., 2003). Twin dyads might be prone to such conflict with their separate partners for a variety of reasons, including their own rearing histories. In the case of one twin, this could lead to divorce and eventual stepfather presence; the other twin might experience a conflicted, but not broken, marriage. In both cases, this would result in accelerated puberty in daughters.

In our sample, maternal age at menarche was a substantial predictor of daughter's age at menarche. Campbell and Udry (1995) observed that maternal menarche better predicted daugh- ter's menarche than contextual stressors such as education and father absence. A similar effect was obtained by Graber et al. (1995), who found that parental warmth and approval continued to be associated with later maturation after controlling for mother's menarcheal age. In fact, the value of the regression coefficient for maternal menarche in our model $(b=.22)$ is similar to that obtained by Campbell and Udry $(\mathrm{b}=.29)$ and Graber et al. $(\mathrm{b}=$ $.23)$.

It is worth commenting on the magnitude of our stepfathering effect. Although a 4- to 6-month acceleration in menarche may seem substantively small, pubertal maturation occurs during a strikingly concentrated and emotionally fragile period of adolescence. Small fluctuations in maturational onset become salient based on the social and emotional consequences to developmental changes. Additionally, early menarche is associated with earlier onset of ovulatory menstruation: The time from menarche until $50 \%$ of menstrual cycles are ovulatory is approximately 1 year if menarche occurs before age 12 but 4.5 years if menarche occurs at 13 or older (Apter \& Vihko, 1983). Thus, even small changes in timing of puberty may have substantial effects on reproductive status risk for teenage pregnancy.

The wholly Caucasian population of our Australian sample may explain our failure to replicate the strong father-absence association observed in more ethnically diverse American samples. Given that African American and Latina girls experience menarche on average 6 months prior to Caucasians (Herman-Giddens et al., 
Table 6

Accelerated Failure Time Models of Stepfathering and Age at Menarche Transformed to Log

\begin{tabular}{|c|c|c|c|c|c|}
\hline Parameter & Model 1 & Model 2 & Model 3 & Model 4 & Model 5 \\
\hline \multicolumn{6}{|c|}{ Random effects } \\
\hline Families & $\begin{array}{l}.00026^{*} \\
(.0001)\end{array}$ & $\begin{array}{l}.00024^{*} \\
(.0001)\end{array}$ & $\begin{array}{l}.00022^{*} \\
(.0001)\end{array}$ & $\begin{array}{l}.00022^{*} \\
(.0001)\end{array}$ & $\begin{array}{l}.00003 \\
(.001)\end{array}$ \\
\hline Twins & $\begin{array}{l}.00028^{*} \\
(.0002)\end{array}$ & $\begin{array}{l}.00029 * \\
(.0002)\end{array}$ & $\begin{array}{l}.00030^{*} \\
(.0002)\end{array}$ & $\begin{array}{l}.00030^{*} \\
(.0002)\end{array}$ & $\begin{array}{l}.00030^{*} \\
(.0002)\end{array}$ \\
\hline Children & $\begin{array}{l}.002 * \\
(.0001) \\
\end{array}$ & $\begin{array}{l}.002^{*} \\
(.0001) \\
\end{array}$ & $\begin{array}{l}.002 * \\
(.0001) \\
\end{array}$ & $\begin{array}{l}.002 * \\
(.0001) \\
\end{array}$ & $\begin{array}{l}.002 * \\
(.0001) \\
\end{array}$ \\
\hline \multicolumn{6}{|c|}{ Fixed effects } \\
\hline Intercept & $\begin{array}{l}1.11 * \\
(.001)\end{array}$ & $\begin{array}{l}1.11 * \\
(.002)\end{array}$ & $\begin{array}{l}1.11 * \\
(.002)\end{array}$ & $\begin{array}{l}1.11 * \\
(.002)\end{array}$ & $\begin{array}{l}1.11 * \\
(.002)\end{array}$ \\
\hline $\begin{array}{l}\text { Stepfathering } \\
\text { Individual child report }\end{array}$ & & $\begin{array}{c}-.012^{*} \\
(.005)\end{array}$ & & & \\
\hline Individual child report deviation & & & $\begin{array}{l}.01 \\
(.01)\end{array}$ & $\begin{array}{l}.01 \\
(.01)\end{array}$ & $\begin{array}{l}.01 \\
(.01)\end{array}$ \\
\hline Twin mother status & & & $\begin{array}{r}-.01 * \\
(.01)\end{array}$ & & \\
\hline Twin mother deviation & & & & $\begin{array}{l}.00011 \\
(.01)\end{array}$ & $\begin{array}{l}.005 \\
(.01)\end{array}$ \\
\hline Family status & & & & $\begin{array}{c}-.02 * \\
(.01)\end{array}$ & $\begin{array}{r}-.013^{*} \\
(.006)\end{array}$ \\
\hline \multicolumn{6}{|l|}{ Maternal menarche } \\
\hline Twin pair mean & & & & & $\begin{array}{l}.007 * \\
(.001)\end{array}$ \\
\hline Twin mother deviation & & & & & $\begin{array}{l}.007 * \\
(.001)\end{array}$ \\
\hline
\end{tabular}

Note. Values in parentheses are standard errors.

$* p<.05$.

1997), it may be that the previously established associations between early menarche and lack of a traditional two-parent family structure are affected by racial differences in family structure. Correlates of early menarche may additionally be complicated by effects of poverty or socioeconomic status. For example, Obeidallah, Brennan, Brooks-Gunn, Kindlon, and Earls (2000) obtained a difference in age of menarche between Caucasian and Latina girls, but this effect disappeared after controlling for socioeconomic status.

One limitation of our study is that it is based on retrospective reports of age at menarche and stepfather status. Although there is evidence to suggest that women can retrospectively report their age at menarche with considerable accuracy (e.g., Bean, Leeper, Wallace, Sherman, \& Jagger, 1979), the reliability of retrospectively reported stepfathering is less precise. Within our sample siblings disagreed in reports of stepfather presence. Our sample also was not randomly selected from the Australian population, having been partially selected from a twin sample targeting the presence of antisocial behavior, divorce, depression, or substance abuse.

The discipline of behavior genetics has also received criticism for its limitations, particularly an overestimation of the consequences of heritability coefficients (Greenberg, 2005) and the disassociation between statistical assumptions of family studies and the developmental mechanisms underlying genetics at a cellular level (Partridge, 2005). Certainly, the need to move beyond strict heritability studies is becoming evident now that there is consensus within the field of psychology that both genes and environment are vital to development (Turkheimer, 2000). It would be futile to disagree that the genetic statistical design has limitations (e.g., in our CoT methodology we are still working on controlling for spousal characteristics, as noted by Eaves, Silberg, \& Maes, 2005). Nevertheless, we believe that behavior genetics studies possess a robust set of unique advantages. Most notably, in the absence of genetically informative designs, family studies are unable to control for unmeasured environmental and genetic processes. Although randomized experimental manipulation of many human developmental circumstances will always be impossible for ethical reasons, behavior genetics methodology enables the quasiexperimental evaluation of mechanisms responsible for associations between risk factors and outcomes. Additionally, because effects of genotype-environment correlations tend to be substantially larger than those of genes alone, behavior genetics studies may be preferable to gene-typing studies owing to their capacity to evaluate genes and environment jointly (Moffitt, 2005).

Our study is the first genetically informed approach to menarche and stepfathering, and our findings highlight the potential of the CoT design. As Rutter et al. (2001) noted, analytic methods that target co-occurring risk processes are essential. The overwhelming advantage of using children of twins in data analysis lies in the potential to disentangle the correlations between development variables not under experimental control. The present study exam- 
ines but one example of an association presumed to be causal through limitations in experimental design and statistical analysis. In particular, D'Onofrio et al. (2006) utilized children of twins to clarify the effects of divorce on a variety of child and adolescent outcomes. Results implicate a causal role for divorce in earlier initiation of sexual intercourse and emotional difficulties, as well as a greater probability of educational problems, depressed mood, and suicidal ideation. In contrast, an earlier initiation of drug use was explained by selection factors, including genetic confounds.

Our results, which fail to support the environmental stress hypothesis, by no means lessen the importance of the literature establishing the detrimental correlates of early pubertal timing. Conversely, it is increasingly imperative to investigate further mechanisms contributing to age at menarche. The quality of the stepfather-daughter relationship and child's age when a stepfather enters the household are likely important mitigating factors (Ellis, 2004; Ellis \& Garber, 2000). A future direction of our research will be to treat menarche not as an outcome but as a predictor. Applying CoT methodology to the presumed consequences of early menarche may prove beneficial in studying the causal role of early menarche in the etiology of outcomes known to be associated with it, such as depression, substance abuse, teen pregnancy, and abortion.

\section{References}

Apter, D., \& Vihko, R. (1983). Early menarche, a risk factor for breast cancer, indicates early onset of ovulatory cycles. Journal of Clinical Endocrinology and Metabolism, 57, 82-86.

Bean, J. A., Leeper, J. D., Wallace, R. B., Sherman, B. M., \& Jagger, H. (1979). Variations in the reporting of menstrual histories. American Journal of Epidemiology, 109, 181-185.

Belsky, J., Steinberg, L., \& Draper, P. (1991). Childhood experience, interpersonal development and reproductive strategy: An evolutionary theory of socialization. Child Development, 62, 647-670.

Blyth, D. A., Simmons, J. K., \& Zakin, D. F. (1985). Satisfaction with body image for early adolescent females: The impact of pubertal timing within different school environments. Journal of Youth and Adolescence, 14, 207-225.

Bryk, A. S., \& Raudenbush, S. W. (1992). Hierarchical linear models: Applications and data analysis methods. Newbury Park, CA: Sage.

Campbell, B. C., \& Udry, J. R. (1995). Stress and age at menarche of mothers and daughters. Journal of Biosocial Sciences, 27, 127-134.

Caspi, A. (1998). Personality development across the life course. In W. Damon (Ed.), Handbook of child psychology (5th ed., pp. 311-388). New York: Wiley.

Caspi, A., \& Moffitt, T. E. (1991). Individual differences are accentuated during periods of social change: The sample case of girls at puberty. Journal of Personality and Social Psychology, 61, 157-168.

Colmenares, F., \& Gomendio, M. (1988). Changes in female reproductive condition following male take-overs in a colony of hamadryas and hybrid baboons. Folia Primatologica, 50, 157-174.

Comings, D. E., Muhlemann, D., Johnson, J. P., \& MacMurray, J. P. (2002). Parent-daughter transmission of the androgen receptor gene as an explanation of the effect of father absence on age of menarche. Child Development, 73, 1046-1051.

Daniels, D., \& Plomin, R. (1985). Differential experience of siblings in the same family. Developmental Psychology, 21, 747-760.

Dick, D. M., Rose, R. J., Viken, R. J., \& Kaprio, J. (2000). Pubertal timing and substance use: Association between and within families across late adolescence. Developmental Psychology, 36, 180-189.

D’Onofrio, B. M., Turkheimer, E., Eaves, L. J., Corey, L. A., Berg, K.,
Solaas, M. H., \& Emery, R. E. (2003). The role of the children of twins design in elucidating causal relations between parent characteristics and child outcomes. Journal of Child Psychology and Psychiatry, 44, 1130 1144.

D’Onofrio, B. M., Turkheimer, E. N., Emery, R. E., Slutske, W. S., Heath, A. C., Madden, P. A., \& Martin, N. G. (2005). A genetically informed study of marital instability and its association with offspring psychopathology. Journal of Abnormal Psychology, 114, 570-586.

D’Onofrio, B. M., Turkheimer, E., Emery, R. E., Slutske, W. S., Heath, A., Madden, P. A. F., \& Martin, N. (2006). A genetically informed study of the processes underlying the association between parental marital instability and offspring adjustment. Developmental Psychology, 42, 486499.

Doughty, D., \& Rodgers, J. L. (2000). Behavior genetic modeling of menarche in U.S. females. In J. L. Rodgers, D. C. Rowe, \& W. B. Miller (Eds.), Genetic influences on human fertility and sexuality: Theoretical and empirical contributions from the biological and behavioral sciences (pp. 170-181). Boston: Kluwer.

Draper, P., \& Harpending, H. (1982). Father absence and reproductive strategy: An evolutionary perspective. Journal of Anthropological Research, 38, 255-273.

Dunn, J., \& Plomin, R. (1990). Separate lives: Why siblings are so different. New York: Basic Books.

Eaves, L. J., Silberg, J. L., \& Maes, H. H. (2005). Revisiting the children of twins: Can they be used to resolve the environmental effects of dyadic parental treatment on child behavior? Twin Research and Human Genetics, 8, 283-290.

Ellis, B. (2004). Timing of pubertal maturation in girls: An integrated life history approach. Psychological Bulletin, 130, 920-958.

Ellis, B. J., \& Garber, J. (2000). Psychosocial antecedents of variation in girls' pubertal timing: Maternal depression, stepfather presence, and marital and family stress. Child Development, 71, 485-501.

Ellis, B. J., McFadyen-Ketchum, S., Dodge, K. A., Pettit, G. S., \& Bates, J. E. (1999). Quality of early family relationships and individual differences in the timing of pubertal maturation in girls: A longitudinal test of an evolutionary model. Journal of Personality and Social Psychology, $77,387-401$

Gottesman, I. I., \& Bertelsen, A. (1989). Confirming unexpressed genotypes for schizophrenia. Archives of General Psychiatry, 46, 867-872.

Graber, J. A., Brooks-Gunn, J., \& Warren, M. P. (1995). The antecedents of menarcheal age: Heredity, family environment, and stressful life events. Child Development, 66, 346-359.

Graber, J. A., Lewinsohn, P. M., Seeley, J. R., \& Brooks-Gunn, J. (1997). Is psychopathology associated with the timing of pubertal development? Journal of the American Academy of Child and Adolescent Psychiatry, $36,1768-1776$.

Greenberg, G. (2005). The problems with behavior-genetic analyses. Developmental Psychology, 41, 989-992.

Heath, A. C., Bucholz, K. K., Madden, P. A., Dinwiddie, S. H., Slutske, W. S., Bierut, L. J., et al. (1997). Genetic and environmental contributions to alcohol dependence risk in a national twin sample: Consistency of findings in women and men. Psychological Medicine, 27, 1381-1396.

Heath, A. C., \& Martin, N. G. (1994). Genetic influences on alcohol consumption patterns and problem drinking: Results from the Australian NH\&MRC twin panel follow-up survey. Annals of the New York Academy of Sciences, 708, 72-85.

Herman-Giddens, M. E., Slora, E. J., Wasserman, R. C., Bourdony, C. J., Bhapkar, M. V., Koch, G. G., \& Hasemeier, C. M. (1997). Secondary sexual characteristics and menses in young girls seen in office practice: A study from the Pediatric Research in Office Settings Network. Pediatrics, 99, 505-512.

Jardine, R., \& Martin, N. G. (1984). Causes of variation in drinking habits in a large twin sample. Acta Geneticae Medicae et Gemellologiae, 33, $435-450$. 
Jones, B., Leeton, J., McLeod, I., \& Wood, C. (1972). Factors influencing the age of menarche in a lower socioeconomic group in Melbourne. Medical Journal of Australia, 2, 533-535.

Keel, P. K., Fulkerson, J. A., \& Leon, G. R. (1997). Disordered eating precursors in pre- and early adolescent girls and boys. Journal of Youth and Adolescence, 26, 203-216.

Kim, K., \& Smith, P. K. (1998). Childhood stress, behavioural symptoms and mother-daughter pubertal development. Journal of Adolescence, 21, 231-240.

Meyer, J. M., Eaves, L. J., Heath, A. C., \& Martin, N. G. (1991). Estimating genetic influences on the age-at-menarche: A survival analysis approach. American Journal of Medical Genetics, 39, 148-154.

Mezzich, A. C., Tarter, R. E., Giancola, P. R., Lu, S., Kirisci, L., \& Parks, S. (1997). Substance use and risky sexual behavior in female adolescents. Drug and Alcohol Dependence, 44, 157-166.

Moffitt, T. (2005). The new look of behavioral genetics in developmental psychopathology: Gene-environment interplay in antisocial behaviors. Psychological Bulletin, 131, 533-554.

Moffitt, T. E., Caspi, A., Belsky, J., \& Silva, P. A. (1992). Childhood experience and the onset of menarche: A test of a sociobiological model. Child Development, 63, 47-58.

Mustanski, B. S., Viken, R. J., Kaprio, J., Pulkkinen, L., \& Rose, R. J. (2004). Genetic and environmental influences on pubertal development: Longitudinal data from Finnish twins at ages 11 and 14. Developmental Psychology, 40, 1188-1198.

Obeidallah, D. A., Brennan, R. T., Brooks-Gunn, J., Kindlon, D., \& Earls, F. (2000). Socioeconomic status, race, and girls' pubertal maturation: Results from the Project on Human Development in Chicago Neighborhoods. Journal of Research on Adolescence, 10, 443-464.

Partridge, T. (2005). Are genetically informed designs genetically informative? Comment on McGue, Elkins, Walden, and Iacono (2005) and quantitative behavioral genetics. Developmental Psychology, 41, 985988

Romans, S. E., Martin, J. M., Gendall, K., \& Herbison, G. P. (2003). Age of menarche: The role of some psychosocial factors. Psychological Medicine, 33, 933-939.

Rowe, D. C. (2000). Environmental and genetic influences on pubertal development: Evolutionary life history traits? In J. L. Rodgers, D. C. Rowe, \& W. B. Miller (Eds.), Genetic influences on human fertility and sexuality: Theoretical and empirical contributions from the biological and behavioral sciences (pp. 148-168). Boston: Kluwer.

Rowe, D. C. (2002). On genetic variation and age at first sexual intercourse: A critique of the Belsky-Draper hypothesis. Evolution and Human Behavior, 23, 365-372.
Rutter, M., Pickles, A., Murray, R., \& Eaves, L. (2001). Testing hypotheses on specific environmental causal effects on behavior. Psychological Bulletin, 127, 291-324.

Slutske, W., Heath, A. C., Dinwiddie, S. H., Madden, P. A. F., Bucholz, K. K., Dunne, M. P., et al. (1998). Common genetic risk factors for conduct disorder and alcohol dependence. Journal of Abnormal Psychology, 107, 363-374.

Stattin, H., \& Magnusson, D. (1990). Pubertal maturation in female development: Vol. 2. Paths through life. Hillsdale, NJ: Erlbaum.

Stice, E., Presnell, K., \& Bearman, S. K. (2001). Relation of early menarche to depression, eating disorders, substance abuse, and comorbid psychopathology among adolescent girls. Developmental Psychology, 37, 608-619.

Surbey, M. (1990). Family composition, stress, and the timing of human menarche. In F. B. Bercovitch \& T. E. Ziegler (Eds.), Socioendocrinology of primate reproduction (pp. 11-32). New York: Wiley-Liss.

Treloar, S. A., \& Martin, N. G. (1990). Age at menarche as a fitness trait: Nonadditive genetic variance detected in a large twin sample. American Journal of Human Genetics, 47, 137-148.

Turkheimer, E. (2000). Three laws of behavior genetics and what they mean. Current Directions in Psychological Science, 9, 160-164.

Turkheimer, E., \& Waldron, M. (2000). Non-shared environment: A theoretical, methodological, and quantitative review. Psychological Bulletin, 126, 78-108.

Udry, J. R. (1979). Age at menarche, at first intercourse, and at first pregnancy. Journal of Biosocial Science, 11, 433-441.

Wei, L. J. (1992). The accelerated failure time model: A useful alternative to the Cox regression model in survival analysis. Statistics in Medicine, 11, 1871-1879.

Wei, L. J., \& Glidden, D. (1996). An overview of statistical methods for multiple event times data in clinical trials. Statistics in Medicine, 16, 833-839.

Wellens, R., Malina, R. M., Roche, A. F., Chumlea, W. C., Guo, S., \& Siervogel, R. (1992). Body size and fatness in young adults in relation to age at menarche. American Journal of Human Biology, 4, 783-787.

Wierson, M., Long, P. J., \& Forehand, R. L. (1993). Toward a new understanding of early menarche: The role of environmental stress in pubertal timing. Adolescence, 28, 913-924.

Received August 6, 2004

Revision received August 30, 2005

Accepted October 23, 2005

\section{E-Mail Notification of Your Latest Issue Online!}

Would you like to know when the next issue of your favorite APA journal will be available online? This service is now available to you. Sign up at http://watson.apa.org/ notify/ and you will be notified by e-mail when issues of interest to you become available! 